\title{
Conditional recurrence-free survival of clinical complete responders managed by watch and wait after neoadjuvant chemoradiotherapy for rectal cancer in the International Watch \& Wait Database: a retrospective, international, multicentre registry study
}

Citation for published version (APA):

Fernandez, L. M., Sao Juliao, G. P., Figueiredo, N. L., Beets, G. L., van der Valk, M. J. M., Bahadoer, R. R., Hilling, D. E., Kranenbarg, E. M. K., Roodvoets, A. G. H., Renehan, A. G., van de Velde, C. J. H., Habr-Gama, A., Perez, R. O., \& International Watch \& Wait Database Consortium (2021). Conditional recurrence-free survival of clinical complete responders managed by watch and wait after neoadjuvant chemoradiotherapy for rectal cancer in the International Watch \& Wait Database: a retrospective, international, multicentre registry study. Lancet oncology, 22(1), 43-50. https://doi.org/10.1016/S14702045(20)30557-X

Document status and date:

Published: 01/01/2021

DOI:

10.1016/S1470-2045(20)30557-X

Document Version:

Publisher's PDF, also known as Version of record

Document license:

Taverne

Please check the document version of this publication:

- A submitted manuscript is the version of the article upon submission and before peer-review. There can be important differences between the submitted version and the official published version of record. People interested in the research are advised to contact the author for the final version of the publication, or visit the DOI to the publisher's website.

- The final author version and the galley proof are versions of the publication after peer review.

- The final published version features the final layout of the paper including the volume, issue and page numbers.

Link to publication

\footnotetext{
General rights rights.

- You may freely distribute the URL identifying the publication in the public portal. please follow below link for the End User Agreement:

www.umlib.nl/taverne-license

Take down policy

If you believe that this document breaches copyright please contact us at:

repository@maastrichtuniversity.nl

providing details and we will investigate your claim.
}

Copyright and moral rights for the publications made accessible in the public portal are retained by the authors and/or other copyright owners and it is a condition of accessing publications that users recognise and abide by the legal requirements associated with these

- Users may download and print one copy of any publication from the public portal for the purpose of private study or research.

- You may not further distribute the material or use it for any profit-making activity or commercial gain

If the publication is distributed under the terms of Article $25 \mathrm{fa}$ of the Dutch Copyright Act, indicated by the "Taverne" license above,

Download date: 26 Apr. 2023 


\title{
Conditional recurrence-free survival of clinical complete responders managed by watch and wait after neoadjuvant chemoradiotherapy for rectal cancer in the International Watch \& Wait Database: a retrospective, international, multicentre registry study
}

\begin{abstract}
Laura M Fernandez, Guilherme P São Julião, Nuno L Figueiredo, Geerard L Beets, Maxime J M van der Valk, Renu R Bahadoer, Denise E Hilling, Elma Meershoek-Klein Kranenbarg, Annet G H Roodvoets, Andrew G Renehan, Cornelis J H van de Velde, Angelita Habr-Gama, Rodrigo O Perez, the International Watch \& Wait Database Consortium*
\end{abstract}

\begin{abstract}
Summary
Background Watch and wait is a novel management strategy in patients with rectal cancer who have a clinical complete response after neoadjuvant chemoradiotherapy. Surveillance of these patients is generally intensive, because local regrowth (with the potential for salvage) occurs in $25 \%$ of patients, and distant metastases occur in $10 \%$ of patients. It is unclear for how long these patients should be followed up. To address this issue, we did conditional survival modelling using the International Watch \& Wait Database (IWWD), which is a large-scale registry of patients with a clinical complete response after neoadjuvant chemotherapy who have been managed by a watch-and-wait strategy.
\end{abstract}

Methods We did a retrospective, multicentre registry study using a dataset from the IWWD, which includes data from 47 clinics across 15 countries. We selected patients (aged $\geq 18$ years) with rectal cancer who had a clinical complete response after neoadjuvant chemotherapy, and who were subsequently managed by a watch-and-wait strategy between Nov 25, 1991, and Dec 31, 2015. Patients who had not achieved a clinical complete response or who had undergone any surgical procedure were excluded. The criteria used for defining a clinical complete response and the specific surveillance strategies were at the discretion of each participating centre. We used conditional survival modelling to estimate the probability of patients remaining free of local regrowth or distant metastasis for an additional 2 years after sustaining a clinical complete response or being distant metastasis-free for 1, 3, and 5 years from the date of the decision to commence watch and wait. The primary outcomes were conditional local regrowth-free survival at 3 years, and conditional distant metastasis-free survival at 5 years.

Findings We identified 793 patients in the IWWD with clinical complete response who had been managed by a watchand-wait strategy. Median follow-up was 55.2 months (IQR 36.0-75.6). The probability of remaining free from local regrowth for an additional 2 years if a patient had a sustained clinical complete response for 1 year was $88 \cdot 1 \%(95 \% \mathrm{CI}$ $\mathbf{8 5} \cdot \mathbf{8 - 9 0} \cdot 9)$, for 3 years was $97 \cdot 3 \%(95 \cdot 2-98 \cdot 6)$, and for 5 years was $98 \cdot 6 \%(97 \cdot 6-100 \cdot 0)$. The probably of remaining free from distant metastasis for a further 2 years in patients who had a clinical complete response without distant metastasis for 1 year was $93 \cdot 8 \%(92 \cdot 3-95 \cdot 9)$, for 3 years was $97 \cdot 8 \%(96 \cdot 6-99 \cdot 3)$, and for 5 years was $96 \cdot 6 \%(94 \cdot 0-98 \cdot 9)$.

Interpretation These results suggest that the intensity of active surveillance in patients with rectal cancer managed by a watch-and-wait approach could be reduced if they achieve and maintain a clinical complete response within the first 3 years of starting this approach.

Funding European Registration of Cancer Care, financed by the European Society of Surgical Oncology, the Champalimaud Foundation Lisbon, the Bas Mulder Award, granted by the Alpe d'HuZes Foundation and the Dutch Cancer Society, the European Research Council Advanced Grant, and the National Institute of Health and Research Manchester Biomedical Research Centre.

Copyright (C) 2020 Elsevier Ltd. All rights reserved.

Introduction

Organ preservation with no immediate surgery, known as the watch-and-wait strategy, in selected patients with a clinical complete response after neoadjuvant chemoradiotherapy is currently at the forefront of rectal cancer management. This strategy is considered as an attractive option to avoid major surgery and the associated morbidity and mortality risks, and functional consequences. ${ }^{1-4}$ However, with the watch-and-wait approach there is a risk for the development of local regrowth, systemic recurrence, or both, despite the initial achievement of a clinical complete response. ${ }^{2}$ Overall, the risk of

\section{(1)}

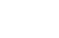

Lancet Oncol 2021; 22: 43-50 Published Online December 11, 2020 https://doi.org/10.1016/ S1470-2045(20)30557-X

*Members of the International Watch \& Wait Database Consortium are listed in the appendix pp 1-2

Colorectal Surgery, Digestive Department, Champalimaud Foundation, Lisbon, Portugal (L M Fernandez MD, N L Figueiredo PhD); Department of Colorectal Surgery, Angelita and Joaquim Gama Institute, São Paulo, Brazil (G P São Julião MD, Prof A Habr-Gama PhD, R O Perez PhD); Department of Surgical Oncology, Hospital Beneficencia Portuguesa, São Paulo, Brazil (G P São Julião, R O Perez); Hospital Alemão Oswaldo Cruz, São Paulo, Brazil (G P São Julião, Prof A Habr-Gama, R O Perez); Department of Surgery, Netherlands Cancer Institute, Amsterdam, Netherlands (Prof G L Beets PhD); GROW School for Oncology and Developmental Biology, Maastricht University, Maastricht, Netherlands (Prof G L Beets); Department of Surgery, Leiden University Medical Center, Leiden, Netherlands

(M) M van der Valk PhD, RR Bahadoer MD, D E Hilling PhD, E Meershoek-Klein Kranenbarg MSc, A G H Roodvoets MSc, Prof (J H van de Velde PhD); Department of Surgery, Erasmus MC, Rotterdam, Netherlands (D E Hilling); Manchester Cancer Research Centre, National Institute of Health and Research, 
Manchester Biomedical Research Centre, Division of Cancer Sciences, School of Medical Sciences, Faculty of Biology, Medicine, and Health, University of Manchester, Manchester, UK (Prof A G Renehan PhD); Colorectal and Peritoneal Oncology Centre, The Christie National Health Service Foundation Trust, Manchester, UK (Prof A G Renehan); University of São Paulo School of Medicine, São Paulo, Brazil (Prof A Habr-Gama); and Ludwig Institute for Cancer Research, São Paulo

Branch, São Paulo, Brazil (R O Perez)

Correspondence to:

Dr Rodrigo O Perez, Department of Colorectal Surgery, Angelita and Joaquim Gama Institute, São Paulo 01327-904, Brazil rodrigo.operez@gmail.com

See Online for appendix

\section{Research in context}

\section{Evidence before this study}

We searched MEDLINE on May 3, 2019, using the search terms "rectal cancer", "Watch and Wait", "non-operative management", AND "wait and see". We searched for articles in English, Portuguese, and Spanish published between Jan 1, 1998 (the year of the first publication of the watch-andwait strategy for rectal cancer) to May 19, 2020 (the date of International Watch \& Wait Database [IWWD] lock). We sought to identify published meta-analyses, pooled analyses, and large-scale registry-based analyses done in patients with a clinical complete response to neoadjuvant chemoradiotherapy who were managed with a watch-and-wait approach.

We identified 13 studies through the literature search. Since the first major study involving patients managed with the watchand-wait approach, most of the available data were, until 2020, from single centres and included a small number of patients. The establishment of the IWWD in 2015, provided the opportunity to investigate the specific features of a larger cohort of patients, who had been managed non-operatively after attaining a clinical complete response, from multiple centres and in real-world settings compared with before this database was established. The only published data from the IWWD reported the actuarial risk for local regrowth at 2 years (25.5\%). As time elapses after attaining a clinical complete response, the risk of local regrowth and distant metastasis is expected to be progressively lower. This effect is captured by conditional survival analysis, which allows accurate estimation of the risk of local regrowth and distant metastasis over time, thus providing useful clinical information to patients and for the design of surveillance strategies. Only one study considered the effect of different risk factors on local regrowth over time, suggesting that some risk factors (eg, baseline clinical tumour [cT] status) might become irrelevant over time, whereas others (eg, type of chemoradiotherapy regimen) might only become relevant later during follow-up, once a clinical complete response has been sustained.

\section{Added value of this study}

To our knowledge, this study involves the largest cohort of patients with rectal cancer who had a clinical complete response after neoadjuvant chemotherapy and were subsequently managed by a watch-and-wait strategy, and in whom the risks of local regrowth and distant metastases over time were examined. Conditional survival modelling allowed us to estimate the risk of local recurrence and distant metastases for an additional 2 years after sustaining a clinical complete response for 1,3 , and 5 years from the date of the decision to commence watch and wait. In addition, our study provides novel information about known risk factors for local regrowth after patients have a sustained clinical complete response. Even though several risk factors could play a major role in the development of local regrowth, as patients sustain a clinical complete response for variable intervals from treatment completion, these risk factors ultimately become irrelevant over time.

\section{Implications of all the available evidence}

Our analysis shows that, after sustaining a clinical complete response for 1 year with a watch-and-wait strategy, risks for local regrowth and distant metastases during the subsequent 2 years are notably low, thus removing the need for intensive surveillance after 3 years. In patients who have a sustained clinical complete response for 1 year, known risk factors (ie, baseline cT status and dose of radiotherapy) for local regrowth appear to become irrelevant thereafter. This observation suggests that the additional treatment of patients with a clinical complete response for the purpose of minimising the risk of local regrowth is unnecessary. Taken together, the information provided by our analysis, which to our knowledge used the largest cohort of patients with rectal cancer with a clinical complete response who were managed by watch and wait, could be important for the design of future trials and for developing guidelines on optimal surveillance strategies and alternative treatment strategies for these patients. local regrowth within 3 years from attaining a clinical complete response is $25-30 \%$, and the occurrence of local regrowth at as long as 7 years from the completion of neoadjuvant chemoradiotherapy has been reported. ${ }^{5,6}$ Therefore, long-term and intensive surveillance protocols have been recommended for patients managed by a watch-and-wait strategy?

The probability of survival and relapse after cancer treatment is typically calculated once for each patient, and usually at the time of completion of therapy. This approach assumes that the risk of recurrence, death, or both is uniformly distributed during the surveillance years. However, patients who remain recurrence-free and survive for a particular period of time appear to have excellent long-term outcomes and remain recurrence-free for an extended time period. ${ }^{8}$ This clinically relevant occurrence is captured and quantified by the concept of conditional survival analysis, which also facilitates the identification of risk factors for disease recurrence that change over time. Particular risk factors could become less or more relevant over time, depending on how long a patient remains recurrence-free during the follow-up period.

The International Watch \& Wait Database (IWWD) is the largest database of patients with rectal cancer who have received neoadjuvant chemoradiotherapy and have been managed by a watch-and-wait approach, and provides the opportunity to study large series of patients in a highly specific clinical setting. ${ }^{4}$ We aimed to analyse the conditional survival of these patients in the IWWD

\section{Methods \\ Study design and participants}

We did a retrospective, multicentre registry study using data obtained from the IWWD, which includes patients 
with rectal cancer who had a clinical complete response after neoadjuvant chemotherapy and were subsequently managed by a watch-and-wait strategy between Nov 25, 1991, and Dec 31, 2015. The IWWD was available for entry of individual patient data on April 14, 2015, and includes data from 47 clinics across 15 countries. Data were entered online at participating centres that agreed to record information on all patients at their institutions who underwent organ-preserving strategies after neoadjuvant treatment for rectal cancer (adenocarcinoma). The IWWD contains information on baseline tumour staging at diagnosis, type of neoadjuvant therapy, final dose of radiotherapy, type of imaging modalities used for staging and reassessment after neoadjuvant chemoradiotherapy, follow-up, the dates and type of treatment after local regrowth or disease recurrence, or both, and survival status.

Only patients aged 18 years and older, who achieved a clinical complete response and were managed by a watch-and-wait strategy alone, were included in our analysis. Clinical complete response was defined as the presence of white scars and telangiectasias, and the absence of any irregularity, mass, ulceration, or stenosis during clinical assessment. In addition, only patients with radiological imaging consistent with complete tumour regression (including the absence of metastatic lymph nodes) were included in the study. However, the precise definition of a clinical complete response and the decision to commence watch and wait were entirely at the discretion of the participating centre. Patients who had not achieved a clinical complete response or who had undergone any surgical procedure were excluded.

\section{Requirements for participant consent, and ethical and institutional review board approval were handled according to the local authorities of participating centres or institutions. Procedures}

To ascertain baseline clinical tumour (cT) stage, we combined data from all radiological imaging modalities done at baseline. If MRI was done, this was considered as the leading imaging modality. The exact radiological imaging modalities used for baseline $\mathrm{CT}$ staging or assessment of response, and the specific findings consistent with a clinical complete response, including the criteria for the absence of metastatic lymph nodes, were entirely at the discretion of each contributing centre. The indication for and type of neoadjuvant therapy used, and the exact surveillance strategy used were also entirely at the discretion of each participating centre. Details of neoadjuvant treatment and follow-up strategies have been described previously., ${ }^{2,10}$

\section{Outcomes}

The main outcome measures were the probability of patients remaining free of local regrowth and distant metastasis for an additional 2 years after sustaining a clinical complete response for 1,3 , and 5 years after the date of the decision to commence watch and wait. The primary (exploratory) endpoints were 2-year conditional local regrowth-free survival at 3 years (after sustaining a clinical complete response for 1 year) and 2-year conditional distant metastasis-free survival at 5 years (after being distant metastasis-free for 3 years). Local regrowth was defined as any reappearance of tumour at the original tumour location or regional lymph nodes, as detected by clinical assessment, endoscopy, or imaging. Distant metastases were defined as the presence of metastatic disease, as identified by radiological evidence or confirmed histologically. Time to local regrowth or distant metastasis was calculated as the time from the date of the decision to commence watch and wait to the time that any recurrence (ie, local regrowth or distant metastasis) was diagnosed.

\section{Statistical analysis}

Local regrowth-free survival and distant metastases-free survival in the study population were estimated by actuarial analysis, and differences in recurrence-free survival were assessed with the log-rank test. Actuarial analysis is used when the actual time of the event (ie, local regrowth or distant metastases) can only be approximated by the endpoint, as opposed to KaplanMeier analysis, which is used when the actual or exact date of the endpoint is known (eg, the date of death for an analysis of postoperative survival). Time to local regrowth and time to distant metastasis were used to create survival curves of local regrowth-free survival and distant metastasis-free survival. Patients were censored at last contact if lost to follow-up or at the date of death due to any cause. Conditional recurrence-free (ie, local regrowth-free and metastasis-free) survival analyses were subsequently used to investigate changes in the probability of recurrence as patients remain recurrencefree after the decision to commence watch and wait, and to assess possible changes in the effect of prognostic factors over time.

Conditional survival was calculated as $P y / x$, where $P y$ is the probability of the patient surviving for additional $y$ years, given that they had already survived for $x$ years, as previously described by Zabor and colleagues. ${ }^{11}$ Actuarial recurrence data were used for these calculations. Conditional recurrence-free survival was calculated for an additional 2 years at 1, 3, and 5 years of being recurrence-free. For instance, the 2-year conditional recurrence-free survival of patients at 1 year can be calculated as the proportion of patients who were alive and recurrence-free at 3 years divided by the proportion of patients who were recurrence-free at 1 year, which provides the proportion of patients who are alive and recurrence-free at 1 year that can be expected to remain alive and recurrence-free after an additional 2 years.

To estimate differences in 2-year conditional recurrence-free survival according to specific prognostic factors, the standardised differences method was used 


\begin{tabular}{|c|c|}
\hline & All patients $(n=793)$ \\
\hline Age, years* & $65 \cdot 0(56 \cdot 0-72 \cdot 0)$ \\
\hline \multicolumn{2}{|l|}{ Sex } \\
\hline Male & $534(67 \%)$ \\
\hline Female & $259(33 \%)$ \\
\hline Tumour size, $\mathrm{mm} \dagger$ & $38 \cdot 0(30 \cdot 0-46 \cdot 0)$ \\
\hline Distance of tumour from the anal verge, $\mathrm{cm} \neq$ & $4 \cdot 0(2 \cdot 5-6 \cdot 0)$ \\
\hline Initial carcinoembryonic antigen concentration, $\mathrm{ng} / \mathrm{mL} S$ & $2 \cdot 5(1 \cdot 3-4 \cdot 0)$ \\
\hline Baseline tumour stage known & $653(82 \%)$ \\
\hline \multicolumn{2}{|l|}{ cT stage } \\
\hline $\mathrm{T} 1$ & $14 / 653(2 \%)$ \\
\hline $\mathrm{T} 2$ & $202 / 653(31 \%)$ \\
\hline T3 & $410 / 653(63 \%)$ \\
\hline T4 & $27 / 653(4 \%)$ \\
\hline Baseline nodal stage known & $674(85 \%)$ \\
\hline \multicolumn{2}{|l|}{ cN stage } \\
\hline $\mathrm{cN}+$ & $386 / 674(57 \%)$ \\
\hline $\mathrm{cN}-$ & $288 / 674(43 \%)$ \\
\hline Union for International Cancer Control stage known & $641(81 \%)$ \\
\hline Stage I & $121 / 641(19 \%)$ \\
\hline Stage II & $138 / 641(21 \%)$ \\
\hline Stage III & $382 / 641(60 \%)$ \\
\hline 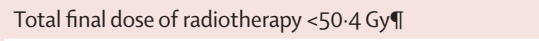 & $249(40 \%)$ \\
\hline Total final dose of radiotherapy, Gy $\mathbb{T}$ & $50 \cdot 4(45 \cdot 0-50 \cdot 4)$ \\
\hline \multicolumn{2}{|c|}{ 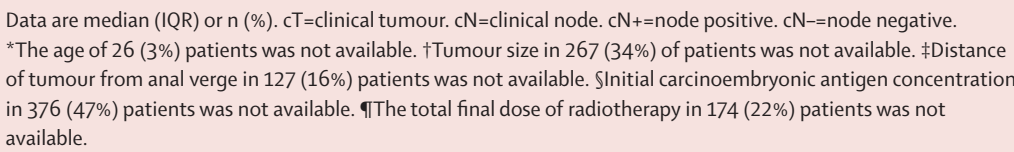 } \\
\hline
\end{tabular}

\begin{tabular}{|lllll|}
\hline & $\begin{array}{l}\text { All patients } \\
(\mathbf{n}=793)\end{array}$ & $\begin{array}{l}\text { Local regrowth-free } \\
\text { at 1 year }(\mathbf{n}=645)\end{array}$ & $\begin{array}{l}\text { Local regrowth-free } \\
\text { at 3 years }(\mathbf{n}=474)\end{array}$ & $\begin{array}{l}\text { Local regrowth-free } \\
\text { at 5years }(\mathrm{n}=\mathbf{2 7 1})\end{array}$ \\
\hline Local regrowth & $212(27 \%)$ & $88(14 \%)$ & $17(4 \%)$ & $4(2 \%)$ \\
CT stage at baseline* & & & & \\
CT1-2 & $40(5 \%)$ & $15(2 \%)$ & $2(1 \%)$ & $1(1 \%)$ \\
CT3 & $114(14 \%)$ & $44(7 \%)$ & $8(2 \%)$ & $1(1 \%)$ \\
CT4 & $9(1 \%)$ & $3(1 \%)$ & 0 & 0 \\
Distant metastases & $85(11 \%)$ & $56(9 \%)$ & $23(5 \%)$ & $13(5 \%)$ \\
Deaths & $138(17 \%)$ & $90(14 \%)$ & $46(10 \%)$ & $21(8 \%)$ \\
\hline
\end{tabular}

Data are $(\%)$. The table shows the number of patients with local regrowth (classified by cT stage at baseline), with distant metastases, and who died as of database lock (May 19, 2020) based on whether they were local regrowth-free at 1, 3, and 5 years. $c T=$ clinical tumour. ${ }^{*}$ The $c T$ stage of 140 (18\%) patients at baseline was not known.

Table 2: Long-term outcomes according to the number of years that patients were free of local recurrence

as described previously. ${ }^{12}$ This method was used to compare the conditional recurrence-free survival between two groups ( 1 and 2$)$, and the standardised conditional recurrence-free survival $(d)$ between these two groups was calculated as follows:

$d=\frac{P 1 N 1+P 2 N 2}{N 1+N 2}$ where $P 1$ and $P 2$ represent the mean probability of conditional recurrence-free survival in the two groups, weighted by the different number $(N)$ of patients in group P1 (N1) and group P2 (N2), according to the previously reported formula. ${ }^{12}$

To estimate differences between 2-year conditional survival curves, effect size was used in a similar manner to what has been described previously. ${ }^{12}$ An effect size of $0 \cdot 3$ or lower indicates small differences between survival curves, an effect size of between 0.3 and 0.5 indicates moderate differences, and an effect size of 0.5 or higher indicates large differences.

Demographic and clinicopathological characteristics, and oncological outcomes of the entire cohort were analysed. Risk factors for local regrowth were estimated by use of Cox regression. Risk factors significantly $(\mathrm{p}<0 \cdot 05)$ associated with local regrowth were used to stratify patients by conditional survival probabilities to estimate the influence of these risk factors over time. Baseline $\mathrm{cT}$ stage and clinical nodal $(\mathrm{cN})$ status, and the final total dose of radiotherapy received, using 50.4 Gy as the cutoff (considered by most guidelines as the upper limit of the recommended standard dose), were evaluated. ${ }^{13,14}$

Considering the long period for inclusion of patients managed by watch and wait in our study, there was an inherent risk of misclassification of baseline $\mathrm{cT}$ and $\mathrm{cN}$ staging features as a function of time. For this reason, we did a stratified post-hoc analysis restricted to patients included in the registry in whom the decision to commence watch and wait was made after Jan 1, 2010. Similar to other previous studies, this post-hoc analysis could potentially provide a more accurate estimate of the effect of baseline features on recurrence-free survival measured by use of contemporary imaging methods, provided that data derived from the MERCURY studies, which showed the high accuracy of MRI for locoregional staging, were fully available and implemented into clinical practice after 2010..$^{10,15}$

Finally, to assess completeness of follow-up, we did a reverse Kaplan-Meier analysis. Using this strategy, censoring of patients were counted as events in order to estimate the completeness of follow-up.

All statistical analyses were done by use of XLSTAT 2020 , 4.1.1023. An arbitrary p value of less than 0.05 was considered as significant.

\section{Role of the funding source}

The funder of the study had no role in study design, data collection, data analysis, data interpretation, or writing of the report. The corresponding author had full access to all of the data and had the final responsibility for the decision to submit for publication.

\section{Results}

We identified 793 patients in the IWWD with rectal cancer who had a clinical complete response after neoadjuvant chemoradiotherapy. Median follow-up was 55.2 months 
(IQR 36 -0-75 -6). Data lock for this report was May 19, 2020. Clinical and radiological features of included patients at baseline are shown in table 1 , and long-term oncological outcomes depending on whether patients were free of local regrowth at 1,3 , and 5 years are in table 2 .

Actuarial local regrowth-free survival in the entire cohort was $83.8 \%(95 \%$ CI $81 \cdot 2-86 \cdot 4)$ at 1 year, $74.3 \%$ $(71 \cdot 1-77 \cdot 4)$ at 3 years, and $72 \cdot 1 \%(68 \cdot 8-75 \cdot 4)$ at 5 years (figure 1). Actuarial distant metastases-free survival in the entire cohort was $97.1 \%$ (95\% CI 96.0-98.3) at 1 year, $91.4 \%(89.3-93.5)$ at 3 years, and $88.9 \%$ $(86 \cdot 5-91 \cdot 3)$ at 5 years (figure 2 ).

2-year conditional local regrowth-free survival estimates the probability of remaining local regrowth-free for an additional 2 years if a patient has a sustained clinical complete response for 1 year (ie, total 3 years), 3 years (total 5 years), and 5 years (total 7 years). 2 -year conditional local regrowth-free survival was $88 \cdot 1 \% \quad(95 \% \quad \mathrm{CI}$ 85.8-90.9) for patients with a clinical complete response at 1 year, $97 \cdot 3 \%(95 \cdot 2-98 \cdot 6)$ for those with a clinical complete response at 3 years, and $98 \cdot 6 \%(97 \cdot 6-100 \cdot 0)$ for those with a clinical complete response at 5 years.

Similar results were observed for distant metastasisfree survival (figure 2). Even though distant metastasis is not a frequent event in general in this setting, ${ }^{6}$ the probability of distant metastasis occurring after 3 years from the decision to commence watch and wait is almost $10 \%$. However, 2-year conditional distant metastasis-free survival in patients who were distant metastasis-free from the decision to commence watch and wait for 1 year was $93.8 \%$ (95\% CI $92 \cdot 3-95 \cdot 9)$, for 3 years was $97.8 \%$ (96.6-99.3), and for 5 years was 96.6\% (94.0-98.9).

Cox regression analyses of the entire cohort showed that, of the parameters tested, the only significant risk factors for local regrowth (measured from the date of the decision to commence watch and wait to local regrowth) were baseline $\mathrm{cT}$ stage and total radiotherapy dose (table 3). After restricting this analysis to patients treated after Jan 1, 2010, a total of 626 patients were identified. The demographics and oncological outcomes of patients according to study period (ie, before and after 2010) are available in the appendix (p 3). No significant difference in the proportion of patients who had local regrowth or distant metastasis was observed between those treated before and after 2010. However, patients treated after 2010 were more likely to be older, have a more advanced tumour stage at baseline, and have received lower doses of radiotherapy compared with those treated before 2010 . Among 626 patients treated after 2010, 573 (92\%) had available baseline cT status information; 180 (31\%) patients were cT1-2 and 393 (69\%) patients were cT3-4. Among this subset of patients, baseline cT status was significantly associated with risk of local regrowth 1 year from the date of the decision to commence watch and wait (actuarial local regrowth-free survival in patients with cT1 or cT2 at baseline was $88 \cdot 0 \%$ [95\% CI 83.2-92.8] compared with $80 \cdot 9 \%[76 \cdot 9-85 \cdot 0]$ in those who were cT3

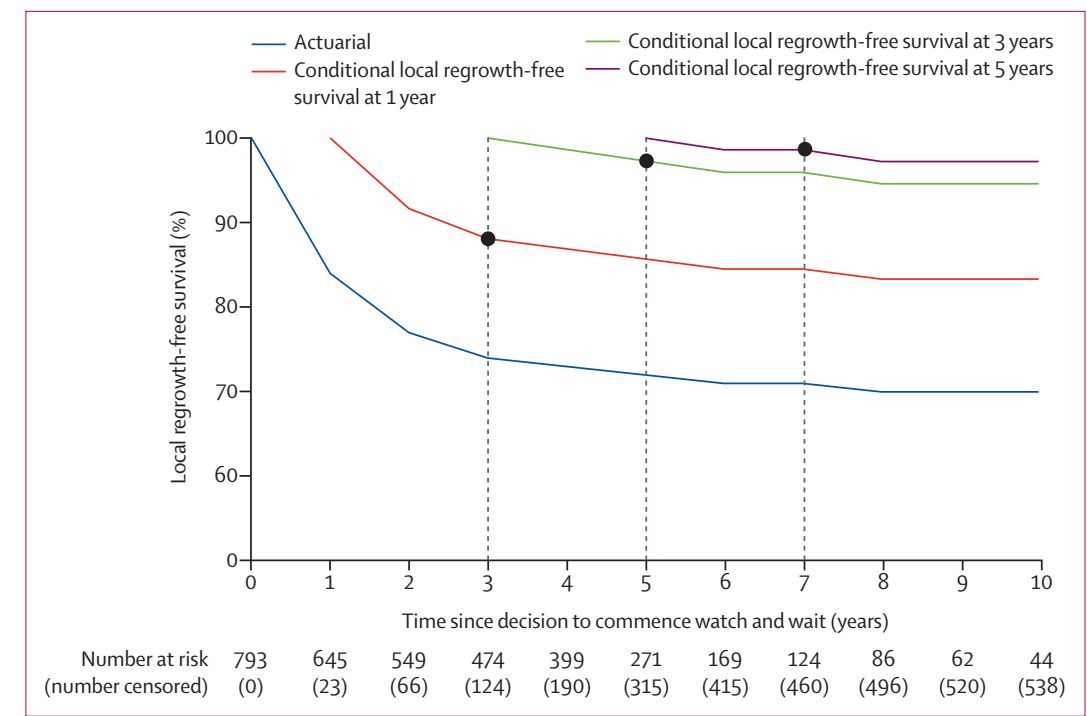

Figure 1: Actuarial and 2-year conditional local regrowth-free survival of patients managed by watch and wait after sustaining a clinical complete response for 1,3 , and 5 years

The black circles represent the probability of remaining local regrowth-free for an additional 2 years once a clinical complete response had been reached and sustained for 1,3 , and 5 years.

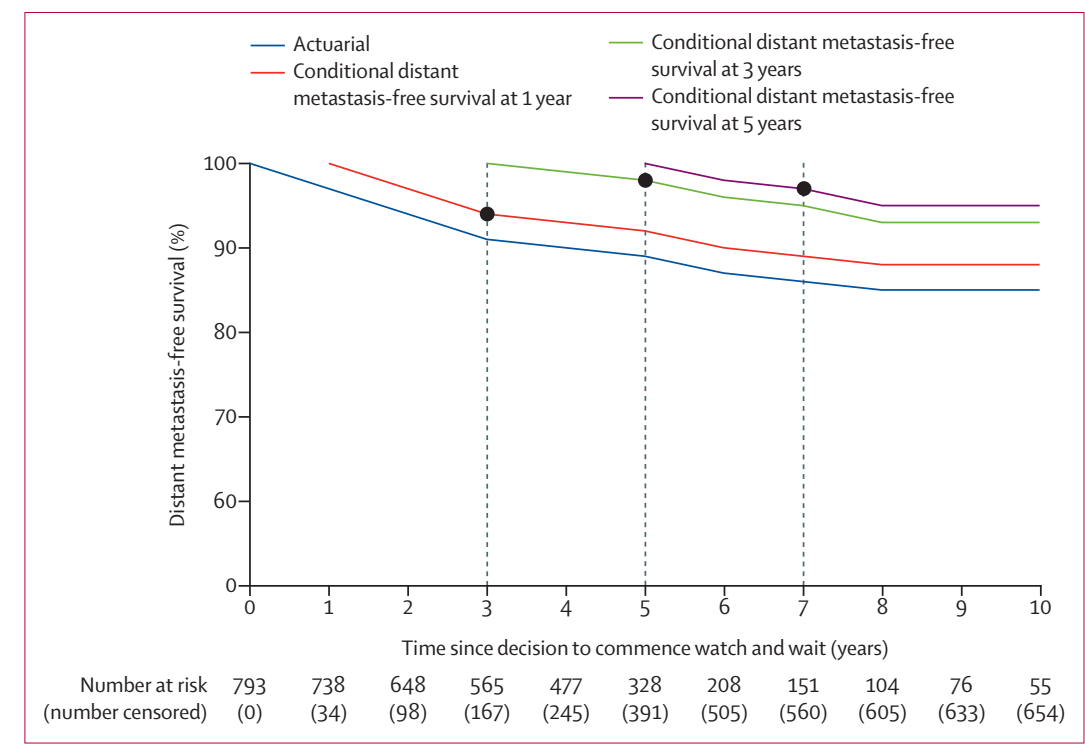

Figure 2: Actuarial and 2-year conditional distant metastasis-free survival of patients managed by watch and wait after remaining distant metastasis-free for 1,3 , and 5 years

The black circles represent the probability of remaining distant metastasis-free for an additional 2 years once patients had been distant metastasis-free for 1,3 , and 5 years.

at baseline; $\mathrm{p}=0 \cdot 0070$; appendix $\mathrm{p}$ 4). However, after a sustained clinical complete response for 1 year, the risk of local regrowth after an additional 1 year was similar between patients with cT1 or cT2 at baseline and those with CT3 at baseline (2-year conditional local regrowthfree survival at 1 year in patients with cT1 or cT2 tumours at baseline was $95 \cdot 4 \%$ [95\% CI 92.7-99.1] compared with $90 \cdot 1 \%[86 \cdot 5-93 \cdot 5]$ in those with cT3 tumours at baseline; effect size $0 \cdot 18$; appendix $\mathrm{p} 4$ ). Similar findings were 


\begin{tabular}{|c|c|c|c|}
\hline & Overall $(n=506)^{*}$ & $\begin{array}{l}\text { Hazard ratio } \\
(95 \% \mathrm{Cl})\end{array}$ & p value \\
\hline Age, years $\dagger$ & $65 \cdot 0(56 \cdot 0-72 \cdot 0)$ & $1.00(0.98-1.01)$ & 0.96 \\
\hline \multicolumn{4}{|l|}{ Sex } \\
\hline Male & 348 (69\%) & $1.39(0.95-2.03)$ & 0.090 \\
\hline Female & $158(31 \%)$ & 1 (ref) & \\
\hline \multicolumn{4}{|l|}{ cT stage } \\
\hline cT1-2 & $156(31 \%)$ & 1 (ref) & \\
\hline cT3-4 & $350(69 \%)$ & $1 \cdot 73(1 \cdot 15-2 \cdot 61)$ & 0.0083 \\
\hline \multicolumn{4}{|l|}{ cN stage } \\
\hline $\mathrm{cN}-$ & $194(38 \%)$ & 1 (ref) & \\
\hline $\mathrm{cN}+$ & $312(62 \%)$ & $0.80(0.56-1.15)$ & 0.24 \\
\hline \multicolumn{4}{|c|}{ Total dose of radiotherapy, Gy } \\
\hline$<50 \cdot 4$ & $238(47 \%)$ & 1 (ref) & \\
\hline$\geq 50 \cdot 4$ & $268(53 \%)$ & $0.60(0.00-0.84)$ & 0.0035 \\
\hline \multicolumn{4}{|c|}{$\begin{array}{l}\text { Data are median (IQR) or } \mathrm{n}(\%) \text {, unless otherwise specified. } \mathrm{cT}=\text { clinical tumour. } \\
\mathrm{cN}=\text { clinical node. } \mathrm{cN}+=\text { node positive. } \mathrm{cN}-=\text { node negative. }{ }^{*} 506(64 \%) \text { of } \\
793 \text { patients had available data for all variables shown in the table. †Assessed as a } \\
\text { continuous variable. }\end{array}$} \\
\hline \multicolumn{4}{|c|}{$\begin{array}{l}\text { Table 3: Cox regression analysis of risk factors for local regrowth in } \\
\text { patients managed by watch and wait }\end{array}$} \\
\hline
\end{tabular}

observed when all patients in the entire cohort (1991-2015) were included in this analysis (appendix p 5).

Similar findings to cT stage were observed for the total dose of radiotherapy. We divided the entire cohort of patients into two groups according to the final total dose of radiotherapy received $(<50 \cdot 4 \mathrm{~Gy} v s \geq 50 \cdot 4 \mathrm{~Gy})$. A total dose of less than 50.4 Gy was significantly associated with a risk of local regrowth at 1 year (actuarial local regrowth-free survival in those who received a final total dose of $<50 \cdot 4$ Gy was $76 \cdot 8 \%$ [95\% CI 71.5-82.1] compared with $85 \cdot 2 \%[81 \cdot 6-88 \cdot 9]$ in those who received $\geq 50.4 \mathrm{~Gy} ; \mathrm{p}=0.014$; appendix $\mathrm{p} 6$ ). However, this difference became less pronounced if patients sustained a clinical complete response for 1 year (1-year conditional local regrowth-free survival in those who received a final total dose of $<50 \cdot 4$ Gy was $93 \cdot 5 \%$ [ $95 \%$ CI $89 \cdot 1-96 \cdot 6$ ] compared with $91.7 \%[87 \cdot 6-94 \cdot 1]$ in those who received $\geq 50 \cdot 4 \mathrm{~Gy}$; effect size $0 \cdot 070$; appendix p 6).

In order to assess completeness of follow-up, we used the reverse Kaplan-Meier method after separating patients into two groups depending on whether they were treated before or after 2010. Patients treated before 2010 were followed up for longer than those treated after 2010, as indicated by the more horizontal inflection of the reverse Kaplan-Meier curve for these patients (appendix p 7). However, both groups showed similar patterns of censoring, as reflected by the vertical components of the reverse Kaplan-Meier curves.

\section{Discussion}

The risk of local regrowth or distant metastases after a clinical complete response to neoadjuvant chemoradiotherapy after non-operative management of rectal cancer remains an important drawback for the widespread uptake of watch and wait in clinical practice. Preserving the rectum in situ after an apparent clinical complete response to chemoradiotherapy with the associated risk of a local regrowth or even distant metastases, led to the recommendation of variable intensive follow-up strategies, often extended over the course of a patient's life, because of the unknown patterns of recurrence. The results of our study suggest that the risk of local regrowth in patients who have a sustained clinical complete response for 3 years is $5 \%$ or less. Another concern associated with nonoperative management of rectal cancer is the risk of developing distant metastases. Our results suggest that the risk of systemic recurrence is low after 3 years of being recurrence-free. Conditional probability of survival provides objective information to patients about the risk of recurrence (local and systemic) over time during follow-up. A few previous studies involving a small number of patients from different clinical settings have tried to address this issue using conditional probability of survival estimates. The use of this approach in a large series of patients could provide relevant information for designing surveillance and follow-up strategies after different treatment modalities. ${ }^{8,12}$

To our knowledge, this multicentre study is the first to estimate the risk of local regrowth and distant metastases over time in a large cohort with long-term follow-up data of patients with rectal cancer who achieve and sustain a clinical complete response for an additional 2 years after reaching this goal at 1,3 , and 5 years follow-up. Based on our findings, intensive surveillance of the rectum for the detection of local regrowth after sustaining a clinical complete response for more than 3 years is unlikely to be required. Patients without any signs of regrowth or distant metastases at 3 years could probably be included in well established follow-up programmes for patients with rectal cancer who undergo standard treatment pathways involving radical resection. Future studies focusing on different surveillance strategies should perhaps consider comparing intensive versus non-intensive approaches for the first 3 years after the patient has a clinical complete response.

Another interesting reflection provided by our results refers to the beginning of watch and wait. In the seminal study by Habr-Gama and colleagues, ${ }^{1}$ watch and wait used the definition of a clinical complete response that was based on sustaining this outcome (measured by clinical or radiological findings) for a minimum of 12 months. ${ }^{1}$ Previous studies have reported that patients who fulfilled this criterion have a risk of local regrowth of nearly $10 \%$ (ie, local regrowth-free survival of almost $90 \%$ ). Our results show that sustaining a clinical complete response for 1 year is associated with a substantial increase in local regrowth-free survival during the subsequent 2 years $(88 \cdot 1 \%)$ compared with actuarial local regrowth-free 
survival at 3 years $(74 \cdot 3 \%)$, estimated from the time of the decision to commence watch and wait. Ultimately, this test of time (proposed as a defining criteria for clinical complete response in the original reports of watch and wait) could be more relevant to the success of watch and wait than other commonly used predictors of a successful outcome, superseding any information provided by baseline, treatment, or reassessment modalities. ${ }^{1}$

In our study, conditional survival estimates also provided interesting findings about changes in risk factors for local regrowth over time in patients who have achieved a clinical complete response. The only significant risk factors for local regrowth in this large cohort of patients were baseline cT stage (tumour-related) and total dose of radiotherapy used (treatment-related). Previous studies have also suggested that baseline cT stage (provided by MRI) is a significant risk factor for local regrowth. ${ }^{16}$ For every increase in cT substage classification, one could expect a nearly $10 \%$ increase in the risk of a local regrowth. ${ }^{10}$ However, a report published in 2020 suggested that such differences between cT2 and cT3 stages might be lost once patients have a sustained clinical complete response for 1 year or longer. ${ }^{9}$ The results of our study suggest that the increased risk for local regrowth in patients with cT3 and cT4 stages is only observed in the first year of follow-up. Even though these results are based on a small number of patients overall (particularly for cT4 disease), our findings support the use of similar surveillance strategies across all cT substages of rectal cancer after the first year that a clinical complete response has been sustained.

Another potential risk factor for local regrowth was the type of neoadjuvant chemoradiotherapy treatment. Patients given high doses (ie, 50.4 Gy) of radiotherapy and additional chemotherapy might more commonly achieve a clinical complete response and have a reduced risk of a local regrowth, as suggested by studies involving contact radiotherapy (ie, delivery of high-dose radiation to the rectal mucosa). ${ }^{17}$ However, our results suggest that, after clinical complete response is sustained for 1 year, the incidence of local regrowth between patients treated with different doses of radiation is similar in the subsequent 2 years. Future prospective studies are needed to understand the exact dose of additional radiotherapy required to potentially decrease the risk of local regrowth in patients who have a clinical complete response.

There are several limitations to the present study that should be considered before any definitive recommendations or changes are implemented into clinical practice. First, heterogeneity in the definitions of a clinical complete response (including clinical, endoscopic, and radiological) could have resulted in the grouping together of patients with near complete or full clinical complete responses (according to strict criteria). Despite this concern, the inclusion of patients with near complete clinical responses might provide a more representative cohort of patients from real-world clinical practice. As identifying patients with a full clinical complete response according to strict criteria takes a substantial amount of time, identification of full clinical complete response is usually retrospective. Notably, sustaining a clinical complete response for 1 year was the original definition of this outcome in early studies of organ preservation strategies. ${ }^{1}$ Second, one could argue that using the date of the decision to commence watch and wait as the start of follow-up, instead of the last date that radiotherapy was received, might have led to an underestimation of the risk of delayed definitive surgical resection of patients with rectal cancer. However, considering that the basic premise for the inclusion of patients managed by a watch-and-wait strategy is having a clinical complete response, using the date of the decision to commence the strategy leads to a restricted and well defined group of patients. Ultimately, objective information provided by the present study will be restricted to patients who have achieved a clinical complete response. Using this method also avoids the potential bias from patients who were assessed at different time intervals from completion of radiotherapy for any reason other than having a clinical complete response and undergoing watch and wait. Third, categorisation of baseline cT staging (the data for which were not available for the whole study population), might have also evolved substantially during the study period (1991-2015), and different methods for exact cT staging (and even cT subclassification) determination could have influenced the results of the study. In particular, important data regarding cT3 subclassification were missing from the IWWD. Future studies should consider data on CT3 subclassification when investigating risk factors for local regrowth over time. The potential changes in accurate staging over the study period are also partly reflected by a substantial age and stage migration over time during the study period. Regardless of these trends, considering notable improvements in imaging modalities over time, the exact influence of stage migration on local regrowthfree survival is difficult to estimate..$^{18}$ Ultimately, baseline staging among patients from small centres might have been overestimated. This effect is unfortunately not captured by the database. Fourth, different surveillance strategies might have influenced the recorded timing of recurrence among different centres. Failure to account for between-centre heterogeneity due to unmeasured factors, such as different protocols for staging, treatments, and follow-up, is an additional study limitation. An individual participant data meta-analysis, which used data from studies in the InterCoRe consortium, addressed this problem with Cox frailty models. ${ }^{10}$ Even though this analysis ${ }^{10}$ concluded that within-centre correlations were significant, estimates from Cox models with and without the frailty extension were similar using data from the InterCoRe consortium; for example, the hazard ratio for local regrowth with increasing cT stage in the post-2008 period $(\mathrm{n}=393)$ was $1.50(95 \%$ CI $1.03-2 \cdot 18)$ using the frailty model versus $1.54(1.07-2 \cdot 22)$ using the model without the frailty extension (Renehan AG, unpublished). 
Finally, even though the effect of radiotherapy dose on local regrowth-free survival was estimated, detailed information on sensitising agents (ie, chemotherapy) was unavailable from the IWWD, thus preventing the inclusion of this variable in the multivariate analysis of risk factors for local regrowth. With the contemporary proposal of multiple total neoadjuvant therapy regimens (including induction and consolidation chemotherapy), which are showing benefits in terms of primary tumour response, information about the exact concomitant chemotherapy regimens that patients included in our analysis were given could have been important for estimating the risk of local regrowth over time. Potential differences in the risk of local regrowth driven by exact neoadjuvant chemotherapy regimens (consolidation or induction) might be resolved by the long-term results of the OPRA trial. ${ }^{19}$

In conclusion, conditional survival analysis estimates suggest that patients who sustain a clinical complete response for 3 years have $5 \%$ or lower risk of developing a local regrowth and a less than $2 \%$ risk of developing systemic recurrence thereafter. Although baseline cT stage and final dose of radiotherapy are known risk factors for local regrowth after an initial clinical complete response to neoadjuvant chemoradiotherapy, these risk factors appear to be less relevant after 1 year of a sustained clinical complete response. Ultimately, the biological information provided by a sustained clinical complete response could override these risk factors. Although a substantial amount of inherent bias derived from large databases warrants cautious interpretation of the results, this information should be taken into consideration when developing surveillance guidelines for patients with rectal cancer undergoing organ-preservation strategies, and for the design of future studies of different treatment strategies, follow-up programmes, and adjuvant therapies.

\section{Contributors}

LMF, GPSJ, NLF, GLB, AGHR, CJHVDV, AH-G, and ROP

conceptualised and designed the study. LMF, MJMVDV, RRB, DEH, EM-KK, and AGHR extracted the data. LMF, GPSJ, NLF, GLB, AGHR, $\mathrm{AH}-\mathrm{G}$, and ROP analysed the data. All authors contributed to data interpretation and drafting of the manuscript, and all authors approved the final manuscript draft.

\section{Declaration of interests}

GPSJ reports personal fees from Johnson and Johnson, Merck Sharpe \& Dohme, Medtronics, Roche, and Merck outside the submitted work.

ROP reports personal fees from Johnson and Johnson, Merck Sharpe \& Dohme, Medtronics, and Roche outside the submitted work. The other authors declare no competing interests.

\section{Acknowledgments}

This study was funded by European Registration of Cancer Care, which is financed by the European Society of Surgical Oncology,

the Champalimaud Foundation Lisbon, the Bas Mulder Award, granted by the Alpe d'HuZes Foundation and the Dutch Cancer Society, the European Research Council Advanced Grant, and the National Institute of Health and Research Manchester Biomedical Research Centre.

\section{References}

1 Habr-Gama A, Perez RO, Nadalin W, et al. Operative versus nonoperative treatment for stage 0 distal rectal cancer following

chemoradiation therapy: long-term results. Ann Surg 2004; 240: 711-18.
2 van der Valk MJM, Hilling DE, Bastiaannet E, et al. Long-term outcomes of clinical complete responders after neoadjuvant treatment for rectal cancer in the International Watch \& Wait Database (IWWD): an international multicentre registry study. Lancet 2018; 391: 2537-45.

3 Renehan AG, Malcomson L, Emsley R, et al. Watch-and-wait approach versus surgical resection after chemoradiotherapy for patients with rectal cancer (the OnCoRe project): a propensity-score matched cohort analysis. Lancet Oncol 2015; 17: 174-83.

4 Beets GL, Figueiredo NL, Habr-Gama A, van de Velde CJ. A new paradigm for rectal cancer: organ preservation: introducing the International Watch \& Wait Database (IWWD). Eur J Surg Oncol 2015; 41: 1562-64.

5 Habr-Gama A, Perez RO, Proscurshim I, et al. Patterns of failure and survival for nonoperative treatment of stage $\mathrm{c} 0$ distal rectal cancer following neoadjuvant chemoradiation therapy. J Gastrointest Surg 2006; 10: 1319-28.

6 Dattani M, Heald RJ, Goussous G, et al. Oncological and survival outcomes in watch and wait patients with a clinical complete response after neoadjuvant chemoradiotherapy for rectal cancer: a systematic review and pooled analysis. Ann Surg 2018; 268: 955-67.

7 Habr-Gama A, Gama-Rodrigues J, São Julião GP, et al. Local recurrence after complete clinical response and watch and wait in rectal cancer after neoadjuvant chemoradiation: impact of salvage therapy on local disease control. Int J Radiat Oncol Biol Phys 2014; 88: 822-28.

8 Karagkounis G, Liska D, Kalady MF. Conditional probability of survival after neoadjuvant chemoradiation and proctectomy for rectal cancer: what matters and when. Dis Colon Rectum 2019; 62: 33-39.

9 São Julião GP, Karagkounis G, Fernandez LM, et al. Conditional survival in patients with rectal cancer and complete clinical response managed by watch and wait after chemoradiation: recurrence risk over time. Ann Surg 2020; 272: 138-44.

10 Chadi SA, Malcomson L, Ensor J, et al. Factors affecting local regrowth after watch and wait for patients with a clinical complete response following chemoradiotherapy in rectal cancer (InterCoRe consortium): an individual participant data meta-analysis. Lancet Gastroenterol Hepatol 2018; 3: 825-36.

11 Zabor EC, Gonen M, Chapman PB, Panageas KS. Dynamic prognostication using conditional survival estimates. Cancer 2013; 119: 3589-92.

12 Cucchetti A, Piscaglia F, Cescon M, et al. Conditional survival after hepatic resection for hepatocellular carcinoma in cirrhotic patients. Clin Cancer Res 2012; 18: 4397-405.

13 Benson AB, Venook AP, Al-Hawary MM, et al. Rectal cancer, version 2.2018, NCCN clinical practice guidelines in oncology. J Natl Compr Canc Netw 2018; 16: 874-901.

14 Glynne-Jones R, Wyrwicz L, Tiret E, et al. Rectal cancer: ESMO clinical practice guidelines for diagnosis, treatment and follow-up. Ann Oncol 2018; 28 (suppl 4): iv22-40.

15 Group MS. Diagnostic accuracy of preoperative magnetic resonance imaging in predicting curative resection of rectal cancer: prospective observational study. BMJ 2006; 333: 779.

16 Habr-Gama A, São Julião GP, Gama-Rodrigues J, et al. Baseline T classification predicts early tumor regrowth after nonoperative management in distal rectal cancer after extended neoadjuvant chemoradiation and initial complete clinical response. Dis Colon Rectum 2017; 60: 586-94.

17 Sun Myint A, Smith FM, Gollins S, et al. Dose escalation using contact $\mathrm{x}$-ray brachytherapy after external beam radiotherapy as nonsurgical treatment option for rectal cancer: outcomes from a single-center experience. Int J Radiat Oncol Biol Phys 2018; 100: 565-73.

18 Sekhar H, Zwahlen M, Trelle S, et al. Nodal stage migration and prognosis in anal cancer: a systematic review, meta-regression, and simulation study. Lancet Oncol 2017; 18: 1348-59.

19 Smith JJ, Chow OS, Gollub MJ, et al. Organ preservation in rectal adenocarcinoma: a phase II randomized controlled trial evaluating 3-year disease-free survival in patients with locally advanced rectal cancer treated with chemoradiation plus induction or consolidation chemotherapy, and total mesorectal excision or nonoperative management. BMC Cancer 2015; 15: 767 